\title{
A FORMAÇÃO CONTÍNUA NAS REPRESENTAÇÕES DE PROFESSORES E GESTORES EM TRÊS MUNICÍPIOS DO INTERIOR PAULISTA
}

\author{
Sônia Regina Guaraldo \\ Universidade de São Paulo - USP, São Paulo, SP. E-mail: soniareginaguaraldo@gmail.com
}

\begin{abstract}
RESUMO
Este artigo é resultado de pesquisa que teve como objetivo discutir a formação contínua em serviço nas representações de gestores e professores em três sistemas municipais de ensino do interior paulista. Descreve brevemente os instrumentos de coleta de dados utilizados para obtenção e análise dos dados no estudo original a partir da perspectiva teórica da antropologia dialética de Henri Lefebvre. Apresenta, por fim, as conclusões da pesquisa que apontam para a mútua interferência entre representações e contexto educacional estabelecendo, em certo sentido, relação entre a existência de boas práticas de formação, representações mais voltadas à prática pedagógica e autonomia dos gestores.
\end{abstract}

Palavras-chave: Representações. Formação Continuada. Autonomia. Prática Pedagógica. Gestão.

\section{THE CONTINUING EDUCATION IN TEACHERS' REPRESENTATIONS AND MANAGERS IN THREE MUNICIPALITIES IN THE COUNTRY SIDE OF SÃO PAULO.}

\begin{abstract}
This article is the result of a research that aimed to discuss the continuing education in service in teachers and managers representations in three municipal education systems in the country side of São Paulo. It briefly describes the data collection instruments used to obtain and analyse the data in the original study from the theoretical perspective of the anthropological dialect of Henri Lefebvre. It presents, finally, the conclusions of the research pointing the mutual interference between representations and educational context establishing, in the sense, the relationship between the existence of good practice of education, representations more focused in the teaching practices and managers' autonomy.

Keywords: Representations. Continuing Education. Autonomy. Teaching Practices. Management.
\end{abstract}




\section{INTRODUÇÃO}

É na perspectiva dos desafios apontados nas novas configurações políticas, legais e administrativas fomentadas pela descentralização das decisões sobre o ensino, aliadas às responsabilidades sinalizadas pela atual LDB, que está inserida a demanda em promover de forma autônoma a formação de professores com vistas à garantia de uma educação de qualidade para todos os alunos.

As políticas de formação continuada desenvolvidas nos municípios têm sido fortemente determinadas por um conjunto de elementos que compõe o atual cenário da educação brasileira, no qual se destacam os avanços no campo do conhecimento, as avaliações censitárias em nível nacional e estadual, as reformas curriculares ocorridas nos anos de 1990, a descentralização do ensino, etc. Essas medidas, importantes por buscarem a superação dos problemas de acesso e permanência, acabaram por descortinar as deficiências nos processos de formação inicial e continuada, uma vez que se reconhece que a qualidade da escolarização oferecida às crianças e jovens entrelaça-se ao desenvolvimento profissional dos professores, em articulação com o trabalho docente.

Das necessidades e dos desafios descritos foi gerada a pesquisa em questão. Assim, o trabalho teve como objetivo geral identificar as principais representações sobre formação contínua em serviço de professores e gestores de três sistemas de ensino do interior paulista doravante identificados como Sistema A, Sistema B e Sistema C. Os objetivos específicos estabelecidos buscaram analisar as formas pelas quais os municípios pesquisados articulam as propostas de formação contínua às necessidades de formação dos professores das respectivas redes e as representações dos professores e gestores desses sistemas, a fim de apreender a imagem que fazem a respeito do processo de formação em serviço.

\section{METODOLOGIA}

A metodologia utilizada se apoiou na perspectiva da antropologia dialética de Henri Lefebvre e seu encaminhamento se deu na direção do que Lefebvre (1985) nos aponta como algumas das regras práticas do método dialético. Tudo está ligado a tudo e que uma interação insignificante, negligenciável por que não essencial em determinado momento, pode tornar-se essencial num outro momento ou sob um ou outro aspecto (LEVEBVRE, 1983).

Nesse sentido, a fim de obter uma gama de dados empíricos e apreender as representações dos profissionais desses três Sistemas, procurou-se utilizar diversos instrumentos de pesquisa, como survey, aplicado a todos os professores do ensino fundamental das três redes, entrevista semi-estruturada, realizada com três gestores (um gestor municipal, um diretor de escola e um coordenador pedagógico), bem como análise de possíveis documentos que pudessem favorecer a compreensão de cada realidade observada, no que tange aos processos de formação contínua dos três sistemas, em especial nos anos de 2012 e 2013 . Todos os dados foram analisados considerando, além das manifestações de gestores e professores em relação ao tema, os aspectos legais e estruturais que compõem o cenário específico de cada um deles.

\section{RESULTADOS}

Os quadros abaixo trazem a síntese dos principais resultados do estudo. O quadro 1 apresenta os aspectos considerados no estudo como relevantes para a compreensão das representações apreendidas e descritas no quadro 2. No próximo tópico, realizaremos a discussão dos elementos descritos nos dois quadros, procurando elucidar a mútua interferência que exercem uns sobre os outros. 
Quadro 01. Principais Aspectos de Interferência na Formação Profissional Nos Sistemas A, B E C

\begin{tabular}{|c|c|c|c|}
\hline & SISTEMA A & SISTEMA B & SISTEMA C \\
\hline \multicolumn{4}{|c|}{ A LEGISLAÇÃO MUNICIPAL E A FORMAÇÃO CONTÍNUA } \\
\hline $\begin{array}{l}\text { Horas de Trabalho } \\
\text { Coletivo na jornada de } \\
\text { trabalho }\end{array}$ & Média de quatro horas & Duas horas & Cinco horas \\
\hline $\begin{array}{l}\text { Progressão funcional via } \\
\text { acadêmica no plano de } \\
\text { carreira }\end{array}$ & Contemplado & Não contemplado & Contemplado \\
\hline $\begin{array}{l}\text { Progressão funcional via } \\
\text { não acadêmica por } \\
\text { entrega de certificados }\end{array}$ & Contemplada & Não contemplada & Contemplada \\
\hline $\begin{array}{l}\text { Afastamentos e licenças } \\
\text { para formação }\end{array}$ & Contemplado & Não contemplado & Contemplado \\
\hline \multicolumn{4}{|c|}{ ESTRUTURA E PRÁTICAS DE FORMAÇÃO } \\
\hline $\begin{array}{l}\text { Estrutura organizacional } \\
\text { da Secretaria de } \\
\text { Educação com } \\
\text { finalidade de promover } \\
\text { formação contínua }\end{array}$ & $\begin{array}{l}\text { Departamento } \\
\text { destinado } \\
\text { exclusivamente à } \\
\text { formação contínua, com } \\
\text { cargos e formas de } \\
\text { provimento previstos em } \\
\text { lei. }\end{array}$ & $\begin{array}{l}\text { Equipe de trabalho para } \\
\text { a formação contínua } \\
\text { atuante com estrutura } \\
\text { improvisada e adaptada. }\end{array}$ & $\begin{array}{l}\text { Equipe atuante na } \\
\text { formação contínua, } \\
\text { cujos cargos em } \\
\text { comissão não preveem, } \\
\text { oficialmente, } \\
\text { atribuições. }\end{array}$ \\
\hline $\begin{array}{l}\begin{array}{l}\text { Diretrizes oficiais de } \\
\text { formação }\end{array} \\
\end{array}$ & Possui & Não possui & Não possui \\
\hline Práticas de formação & $\begin{array}{l}\text { Poucos cursos } \\
\text { oferecidos e organizados } \\
\text { pela secretaria. Repasse } \\
\text { de dois cursos - PNAIC e } \\
\text { Ler e Escrever - no ano } \\
\text { de } 2012 \text { e } 2013 \text {. }\end{array}$ & $\begin{array}{l}\text { Ampla oferta de cursos e } \\
\text { oficinas organizados pela } \\
\text { secretaria de educação, } \\
\text { por parceiros } \\
\text { contratados e em } \\
\text { parceria } \\
\text { Universidade e outras } \\
\text { esferas governamentais. }\end{array}$ & $\begin{array}{l}\text { Pouca oferta de cursose } \\
\text { oficinas. Predominam } \\
\text { ações em parceria com } \\
\text { outras esferas } \\
\text { governamentais, como a } \\
\text { realização do PNAIC. }\end{array}$ \\
\hline $\begin{array}{l}\text { Orientações centrais } \\
\text { para os momentos } \\
\text { coletivos de formação }\end{array}$ & $\begin{array}{l}\text { Ocorrem basicamente } \\
\text { através das orientações } \\
\text { do programa Ler e } \\
\text { Escrever, organizado } \\
\text { pela secretaria de } \\
\text { educação junto aos } \\
\text { coordenadores } \\
\text { pedagógicos. }\end{array}$ & $\begin{array}{l}\text { Orientado através de } \\
\text { reuniões } \\
\text { realizadas semanais } \\
\text { secretaria de educação } \\
\text { com os coordenadores } \\
\text { pedagógicos, com } \\
\text { autonomia para as } \\
\text { unidades modificarem as } \\
\text { propostas. }\end{array}$ & $\begin{array}{l}\text { Orientado através de } \\
\text { reuniões semanais } \\
\text { realizadas } \\
\text { secretaria de educação } \\
\text { com os coordenadores } \\
\text { pedagógicos, com } \\
\text { autonomia para as } \\
\text { unidades modificarem } \\
\text { suas práticas. }\end{array}$ \\
\hline \multicolumn{4}{|c|}{ IDEB } \\
\hline Desempenho & $\begin{array}{l}\text { Crescimento sensível, } \\
\text { sem alcance das metas. }\end{array}$ & $\begin{array}{l}\text { Crescimento sustentado } \\
\text { com alcance das metas. }\end{array}$ & $\begin{array}{c}\text { Crescimento com } \\
\text { oscilações e alcance de } \\
\text { metas. }\end{array}$ \\
\hline $\begin{array}{c}\text { Interferência na } \\
\text { formação contínua }\end{array}$ & $\begin{array}{l}\text { Não direciona ações de } \\
\text { formação. }\end{array}$ & $\begin{array}{l}\text { Direciona ações de } \\
\text { formação. }\end{array}$ & $\begin{array}{l}\text { Direciona ações de } \\
\text { formação. }\end{array}$ \\
\hline
\end{tabular}


Quadro 2. Representações de Gestores e de Professores dos Sistemas A, B E C

\begin{tabular}{|c|c|c|c|}
\hline & SISTEMA A & SISTEMA B & SISTEMA C \\
\hline Gestores & $\begin{array}{l}\text { Tendência em repassar } \\
\text { a outros as principais } \\
\text { decisões robre } \\
\text { formação contínua no } \\
\text { município. Formação } \\
\text { contínua r como } \\
\text { responsabilidade de } \\
\text { outrem. }\end{array}$ & $\begin{array}{l}\text { Formação contínua } \\
\text { como forma de melhorar } \\
\text { os resultados do } \\
\text { Sistema, no caso da } \\
\text { gestora municipal e } \\
\text { diretora de escola. } \\
\text { Coordenadora } \\
\text { pedagógica tende a } \\
\text { repassar as } \\
\text { responsabilidades pela } \\
\text { inovação no campo da } \\
\text { formação. }\end{array}$ & $\begin{array}{l}\text { Formação contínua } \\
\text { como meio de melhorar } \\
\text { os resultados do } \\
\text { Sistema, no caso do } \\
\text { gestor municipal e da } \\
\text { coordenadora } \\
\text { pedagógica, que, assim } \\
\text { como a Diretora de } \\
\text { escola, demonstram } \\
\text { pouca autonomia na } \\
\text { condução das propostas } \\
\text { de formação. }\end{array}$ \\
\hline Professores & $\begin{array}{l}\text { Motivações } \\
\text { expectativas sobre } \\
\text { formação contínua com } \\
\text { tendência de ligação } \\
\text { aos benefícios na } \\
\text { carreira. }\end{array}$ & $\begin{array}{lr}\text { Motivações } & \text { e } \\
\text { expectativas } & \text { sobre } \\
\text { formação contínua mais } \\
\text { ligadas à } \\
\text { pedagógica. }\end{array}$ & $\begin{array}{l}\text { Motivações } \\
\text { expectativas pouco } \\
\text { manifestas, com } \\
\text { indícios de ligação com a } \\
\text { prática pedagógica. }\end{array}$ \\
\hline
\end{tabular}

\section{DISCUSSÃO}

O levantamento dos dados relativos aos cenários investigados e a análise das manifestações de gestores e professores evidenciou realidades distintas no que concerne aos modelos de estruturação das carreiras, às configurações das propostas de formação contínua e à estrutura de formação observada nos referidos sistemas de ensino.

A análise do referido conjunto nos permitiu perceber que os bons espaços de formação verificados nos Sistemas $A$ e $C$, constituídos por horas da jornada de trabalho destinadas à formação, bem como pelas vantagens obtidas em decorrência da participação em cursos de formação, dentre outros fatores citados, encontram-se subaproveitados, uma vez que as condições existentes proporcionariam, em tese, boas oportunidades para o desenvolvimento de propostas de formação mais autônomas do que as observadas.

No Sistema A, a escassez de propostas de formação organizadas pela secretaria de educação evidenciou-se, não tendo sido percebida a autonomia do Sistema, nem o envolvimento dos sujeitos responsáveis na construção de um projeto de formação para o município. No Sistema $C$, ainda que se tenha observado uma presença sensivelmente mais marcante na condução de seus projetos de formação, estes se caracterizavam pela dispersão e fragmentação, evidenciandose nas falas dos gestores certa falta de clareza em relação ao que se pretende com a formação desenvolvida.

Por outro lado, a ausência de oportunidades semelhantes às verificadas nos Sistemas A e C não pareceu oferecer aos gestores do Sistema B obstáculos intransponíveis para uma formulação mais autônoma, em maior quantidade e qualidade que os demais. A inexistência de espaços similares pareceu não impedir ao Sistema a ampla oferta de cursos e oficinas, sendo percebida, ainda que pontuais, a ocorrência de posturas e propostas inovadoras.

No caso dos gestores escolares, os conteúdos formaram dois conjuntos semânticos distintos: um que corresponde a uma visão da formação contínua como meio de melhorar os resultados do sistema e outro formado por um conjunto de ideias através das quais se percebe pouco ou nenhum sentido de responsabilidade profissional pela autoria e autonomia na promoção da formação contínua oferecida no seu âmbito de atuação.

No primeiro conjunto, fundamentado na perspectiva de formação contínua como um meio de melhorar os resultados do Sistema, desvelaram-se tendências e encaminhamentos distintos no 
Sistema B e C, nos quais parte de seus gestores pareceram atribuir este significado aos processos de capacitação profissional que desenvolvem.

A representação de formação como elemento de melhoria dos resultados surge, a nosso ver, como resposta às pressões originadas a partir de diversos elementos presentes no social e que interferem no cotidiano das escolas e dos sistemas municipais de ensino. O que nos parece é que o elemento central desse conjunto de pressões está focado no IDEB. "A melhoria da qualidade do ensino tende, assim, a se traduzir, em última análise, no seu equacionamento em termos da capacidade de alcançar um bom resultado na pontuação do IDEB" (BARRETO, 2012, p.745).

Concordamos com Penin (1995, p.10) sobre a necessidade de compreender como os "sujeitos" reagem às representações presentes no coletivo entendendo-se "ainda que é a forma que toma essa reação do sujeito (mimese ou práxis), e não suas representações, que introduz no social novos elementos, nele interferindo".

Conforme sinaliza Lefebvre (1983), as representações não são falsas, nem verdadeiras, mas sinalizam uma realidade, podendo orientar ações e tomar forma. No caso dos quatro gestores entrevistados, as representações de formação contínua como meio de melhorar os resultados do ensino parecem orientar suas ações em direções variadas, ganhando forma, objetivando-se. A análise das representações desses sujeitos sugere que apenas em relação à gestora escolar (diretora de escola) do Sistema B tal objetivação parece possível de gerar conhecimento novo. Suas mudanças de postura na condução das ações de formação contínua na unidade onde atua revelam tentativas de superação da realidade observada, através da atitude crítica presente em suas condutas e na maneira de conceber o papel do professor na construção de seus saberes pedagógicos, o que, a nosso ver, pode constituir-se no germe da mudança, no sentido que nos propõe Lefebvre (1983). Já no caso da gestora municipal do mesmo sistema, seu saber crítico bem formulado e explicitado em suas manifestações não sugere articulação diferenciada com outros aspectos da realidade vivida de modo a permitir identificar ações ou objetivações inovadoras uma obra, conforme conceito de Lefebvre. Ou seja, mesmo entendendo a necessidade de formação contínua e mesmo atuando como uma das propositoras de diversos cursos e oficinas de formação no município - o que revela um saber teórico bem estruturado (ou concebido, conforme Lefebvre) -, ela parece considerar pouco a importância e o protagonismo do professor no seu processo de formação contínua. Parece faltar a essa gestora, apesar do seu saber, uma atitude crítica, na qual o sujeito do ensino (o professor) e sua vivência na relação com os sujeitos da aprendizagem (alunos) devem ser considerados em propostas de capacitação profissional.

No caso do gestor municipal do sistema $\mathrm{C}$ e da coordenadora pedagógica do mesmo sistema, suas representações parecem tomar a forma de outras representações, conduzindo as ações em um sentido oposto ao que se desejaria, uma vez que não foram observadas propostas que pudessem constituir-se em verdadeiros processos de formação contínua. Apesar de atribuírem a essa formação um sentido de melhoria nos resultados, pouco se mostram como responsáveis pela inovação, demonstrando pouca autonomia frente às suas responsabilidades de formadores.

Tal posicionamento compõe o conteúdo do segundo conjunto semântico, no qual se enquadram os gestores dos Sistemas A e C, e a coordenadora pedagógica do Sistema B. As manifestações desses profissionais nos revelaram, independente da área de atuação de cada um deles, uma constante reprodução de práticas cujos resultados mais se assemelham a produtos que a obras, conforme o conceito de Lefebvre.

A autonomia que proclamam em seus discursos parece de fato não existir, uma vez que o conjunto de ações de formação descrito parece orientar-se por uma perspectiva já determinada anteriormente por outras instâncias administrativas. Desse modo, suas representações sobre formação contínua os aproximam do modelo de profissional que Contreras denomina expert infalível (CONTRERAS, 1999). Segundo o autor, "sua autonomia é enganosa e se baseia no 
entendimento do ensino [...] como aplicação técnica, como prática dirigida à obtenção de resultados ou produtos previamente definidos, não é uma prática criativa, e sim apenas reprodutiva [...]". (CONTRERAS, 1999, p. 101)

Ao proclamarem uma autonomia aparentemente ilusória, revelam ora atitudes conformadas e de aprovação dos modelos que se apresentam, ora apatia e insatisfação. Ocorre que, mesmo aqueles que desaprovam o modelo e se mostram desconfortáveis em relação às formas de conduzir a formação contínua, como é o caso da coordenadora pedagógica do Sistema A, não parecem seguros ou incentivados a ousar, a enfrentar possíveis imprevistos que qualquer ação que se propõe à mudança pressupõe. O conformismo de alguns ou inconformismo de outros parece justificar-se no pressuposto de que pensar formas inovadoras de formação, participando ativamente de um planejamento que se volte para cada realidade específica, não é uma tarefa que Ihes cabe.

Além disso, está claro para nós que a aparente passividade e a apatia desses gestores nascem a partir de contextos variados, cujas configurações nos propõem também explicações diversas. Ampliando a definição de cultura como matriz imutável é preciso reconhecê-la como uma ordem humana que se especifica numa diversidade de aparências, variando de uma sociedade para a outra e entre os grupos de uma mesma sociedade (FORQUIM, 1993).

\section{CONCLUSÃO}

As representações apreendidas de gestores e professores justificam-se a partir das respostas encontradas nas configurações locais, da observação da maneira de conduzir os processos de formação, a partir da organização das secretarias de educação no que tange à estrutura oferecida para a formação contínua, da organização legal de incentivo à participação dos professores nesses processos educativos.

Dessa forma, sem desconsiderar as influências em âmbito mais geral que modificam as formas de pensar, sentir e agir em relação ao tema, parece claro que a cultura de condução das políticas locais de formação tem determinado as representações sobre formação contínua desses profissionais, ao mesmo tempo em que é por elas determinada e constituída ao longo de suas histórias particulares.

Nesse mesmo sentido, vimos, ao apreender as representações sobre formação contínua dos professores dos três sistemas, que estas se ligavam de forma mais qualitativa à prática pedagógica nos contextos em que a dimensão pedagógica se apresentava de maneira mais significativa nos processos, como é o caso do Sistema B. Nessa mesma perspectiva, a ausência de propostas inovadoras de formação nos demais Sistemas parece refletir representações sobre formação contínua mais voltadas aos benefícios salariais e às evoluções na carreira, sobressaindo nessas mesmas representações os aspectos quantitativos e de ordem prática.

Dessa maneira, nosso pressuposto é que os processos de condução das formações, especialmente o "como" as redes planejam, executam e acompanham seus programas de capacitação profissional, podem estar determinando as representações de seus profissionais em relação ao tema.

Tais aspectos sinalizam para a necessidade de que sejam abandonadas as formas tradicionais de capacitação profissional e para a urgência de mudanças culturais nas instituições, o que exigiria dos sistemas de ensino novas posturas na condução de seus projetos de formação contínua, com ênfase na autonomia das escolas e na participação dos professores, sem excluir a função das secretarias de educação como principais motivadores de um formato mais colaborativo de formação.

Compreendemos como natural o posicionamento dos professores ao reconhecer a necessidade de que as formações sejam incluídas nos incentivos à carreira. No entanto, é preciso 
cautela, uma vez que há o risco de que a formação possa ser vista unicamente como incentivo salarial ou de promoção.

Em síntese, concluímos que as manifestações sobre as motivações dos professores dos três sistemas quanto à participação na formação contínua nos levam ao desvelamento de representações sobre formação contínua como um caminho de melhoria da prática pedagógica, mas também como uma forma para a obtenção de vantagens na carreira.

Não se pretendeu, com o estudo, resolver as contradições que se apresentam, apenas apontá-las. Os cenários são distintos, revelando diferentes configurações de carreira e propostas de formação. Além disso, são as formas utilizadas pelas redes para por em prática os artifícios que têm a seu dispor para o desenvolvimento de programas de formação que parecem estar interferindo sobremaneira no modo de pensar e agir dos seus profissionais em relação ao seu processo de formação.

\section{REFERÊNCIAS}

BARRETO, Elba Siqueira de Sá. Políticas de Currículo e Avaliação e Políticas Docentes. Cadernos de Pesquisa. no42. p.738-753. Dez. 2012.

BRASIL. Lei № 9.394, de 20 de dezembro de 1996. Lex: Leis de Diretrizes e Bases da educação Brasileira (LDB), Brasília, 1996.

CONTRERAS, José. A autonomia de professores. São Paulo: Cortez, 1999. 296 p. 15,5 x 22,5 cm.

FORQUIN, Jean-Claude. Escola e Cultura: as bases sociais e epistemológicas do conhecimento escolar. Porto Alegre: Artmed, 1993.

LEFEBVRE, Henri. La presencia y la ausencia - contribuición a la teoria de las represenaciones. México: Fondo de Cultura Económica, 1983. edição original: 1980.

PENIN, Sonia Teresinha de Sousa. A professora e a construção do conhecimento sobre o ensino. Cad. Pesq., São Paulo, n.92, p. 5-15, fev. 1995. 